\title{
THE ROLE OF SELF-EFFICACY IN PREDICTING USE OF DISTANCE EDUCATION TOOLS AND LEARNING MANAGEMENT SYSTEMS
}

\author{
Dr. Ibrahim ARPACI \\ Faculty of Education \\ Gaziosmanpasa University \\ Tokat, Turkey
}

\section{ABSTRACT}

This study aims to investigate the role of self-efficacy in predicting students' use of distance education tools and learning management systems (LMSs). A total of 124 undergraduate students who enrolled in a course on Distance Education and selected using convenience sampling willingly participated in the study. The participants had little prior knowledge about distance education tools and LMSs. Therefore, they received instructions from the researcher over the course of a semester. The study proposed a research model based on the Technology Acceptance Model that has been widely used to predict user acceptance and use. Structural equation modelling was used to test the research model against the data collected through questionnaire surveys. Pretest-posttest results suggested that the students had significant learning by participating in the instruction. The results of the main analysis also suggested that self-efficacy positively affects perceived ease of use, while usefulness and ease of use perceptions positively affect attitudes toward using distance education tools and systems. Implications are provided along with limitations of the study discussed.

Keywords: Distance education, self-efficacy, authoring tools, learning management systems

\section{INTRODUCTION}

Distance education is "a planned learning that normally occurs in a different place from teaching and requires special instructional techniques, special techniques of course design, special methods of communication via technology, and special organizational and administrative arrangements" (Moore \& Kearsley, 1996). Schlosser and Simonson (2002) emphasized on the technologies used and defined distance education as "an institutionbased formal education, where the learning group is separate and interactive telecommunication systems are used to connect learners, resources, and instructors."

Instructional designers in distance education must provide the required course structure to satisfy student needs and ensure students attain the required standards in learning excellence (Saba, 2000). Students are more likely to drop courses when they receive no feedback about their progress, they may become frustrated with completing the course, they think the course is too difficult and the content is irrelevant, or they become isolated since they have limited interaction with their instructors and peers (Moore \& Kearsley, 1996). Thus, interaction is critically important for student motivation and satisfaction as well as maintaining their persistence in distance learning (Berge, 1999).

Interactive tools and systems may provide instructional designers to modify a course structure and set an appropriate level of interactivity to meet learner needs (Flottemesch, 
2000). The success of distance education therefore depends on the ability of instructional designers to provide student satisfaction and retention (Saba, 1999). Accordingly, instructional designers in distance education should have a broad background in instructional design and distance learning theory, have both technical and soft skills, and have a willingness to learn emerging information and communication technologies (Ritzhaupt \& Kumar, 2015).

Self-efficacy is a key concept in socio-cognitive theory and refers to "a person's selfevaluation of his ability to execute the courses of action required for the successful attainment of a certain goal" (Bandura, 1977, 1997). Self-efficacy is a useful lens for researchers in predicting persistence, emotional reaction and effort (Zimmerman, 2000). The role of self-efficacy in successful experiences of distance education has been a frequent theme of recent research. For example, Kozar, Lum, and Benson (2015) investigated the relationship between self-efficacy and vicarious learning in PhD studies at a distance. Their results suggested the more opportunities to engage in meaningful contact, the stronger the students' self-efficacy in completing their degree, and the more satisfying will be their experience. Similarly, Cho and Shen (2013) investigated the role of self-efficacy and goal orientation in student achievement in an online course. Their results indicated the importance of individuals' self-efficacy and intrinsic goal orientation in academic achievement. In another study, Dunn, Rakes, and Rakes (2014) investigated the impact of critical thinking, self-regulation, and age on online students' help-seeking. The results suggested a positive correlation between self-regulation and critical thinking with helpseeking, and a negative correlation between age and help-seeking.

Wang, Shannon, and Ross (2013) investigated the relationships among technology selfefficacy, self-regulated learning, and course outcomes in an online learning. Their results suggested that the higher the levels of motivation in online courses, the higher the levels of technology self-efficacy and course satisfaction. Recently, Lee (2015) investigated whether self-efficacy and task value change over the course of a semester. The results suggest that self-efficacy in course content and online technologies fluctuated, while task value remained unaffected over the course of the semester.

Review of the literature emphasizes the importance of the individual characteristics such as self-efficacy, self-regulation, and autonomy in distance education. However, there is a limited number of studies that investigated the effect of individual characteristics on use of distance education tools and systems. Thereby, the present study contributes to the literature by investigating the role of self-efficacy in predicting the use of distance education tools and systems.

\section{TOOLS AND SYSTEMS USED IN DISTANCE EDUCATION}

\section{Screen Capturing Tools}

Screen capturing tools are used to capture the computer screen by recording the mouse movements, clicks, and keystrokes along with narration. Captivate is a typical example of sophisticated screen capturing tool used to create distance learning materials with audio, visual, and interactivity. This tool can be used to create demonstrations, simulations, scenarios, and quizzes in different file formats. Furthermore, it can be used to create screencasts, and thereby, enables digitally created contents to be followed for later views. Similarly, Camtasia is a screen capturing tool used to create digital contents appropriate for distance learning. Recording screen movements and actions, importing high quality videos from different sources such as camera, customizing and editing the digital content from different platforms, and sharing the contents across multiple devices are the main functionalities of this tool. 


\section{Authoring Tools}

An authoring tool is a collection of software that allows authors to create or modify web content. Authoring tools are an essential element in achieving a universal and accessible web. I-Spring is an example of authoring tool that is built for providing an environment to create e-learning courses. The tool has the capability of converting the PowerPoint slides into a Flash or HTML5 by preserving the effects of transitions, complex animations, and triggers. Thereby, PowerPoint-based courses make slides can be turned into professional training courses with interactive quizzes, audio and video narrations, and screencasts. Similarly, Articulate Studio is an authoring tool that allows authors to narrate, create, and annotate e-learning content in PowerPoint, add surveys, quizzes, media-rich interactions to online courses, and create training videos by recording screencasts.

\section{Learning Management Systems}

LMS is an integrated set of software that allows the administration, tracking, reporting, documentation, and delivery of e-learning courses or distance education programs. There are several LMSs with standard features that can be used for distance education, blended learning, and e-learning. For example, Moodle "Modular Object-Oriented Dynamic Learning Environment" is an open source LMS enabling educators to create online learning environments filled with dynamic courses. Based on a constructivist and social constructionist approach, Moodle aims to provide a virtual learning environment with several plugins, integrations, and collaborative tools to address specific learner needs. Similarly, Sakai is an open source LMS that aims to provide a flexible and feature-rich environment for learning, teaching, research, and collaboration. Edmodo also provides a free blended learning classroom for teachers and students by fostering communication and social learning.

Docebo is a cloud platform for e-learning, which includes authoring tools, real-time collaboration, curriculum management, and reporting capabilities. With the cloud-based nature of this LMS, there is no software to install, and more importantly, it automatically updates itself whenever there is a new update available. However, Docebo is free of charge for groups up to five users. ALMS is also a licensed LMS used by more than $\mathbf{3 0}$ universities in Turkey. ALMS is distinguished from others by allowing users to connect on social media.

\section{Virtual Classroom Systems}

Virtual classroom systems are online environments that allow users to interact with learning resources, view presentations, communicate, and work in groups. Virtual classrooms provide a synchronous learning environment by allowing LMS integrations. BigBlueButton is an open source virtual classroom system that enables users to share documents, webcams, chat, audio, and desktop. Lectures can be recorded for later playback by students and whiteboard controls let users annotate and call out key parts of the presentation for viewers. Similarly, Adobe Connect offers online meeting experiences for large scale webinars, group collaboration, lecturing, or office hours. Lastly, Perculus is one of the virtual classroom systems that enable users to join online courses.

\section{THEORETICAL BACKGROUND AND HYPOTHESES}

This study used the Technology Acceptance Model (TAM) developed by Davis (1989) as an initial theoretical framework. The research model shown in Figure 1 suggests that actual use of distance education tools and systems is predicted by behavioral intentions, which are predicted by attitudes. While, the attitudes are predicted by perceived usefulness and perceived ease of use that is predicted by self-efficacy. 


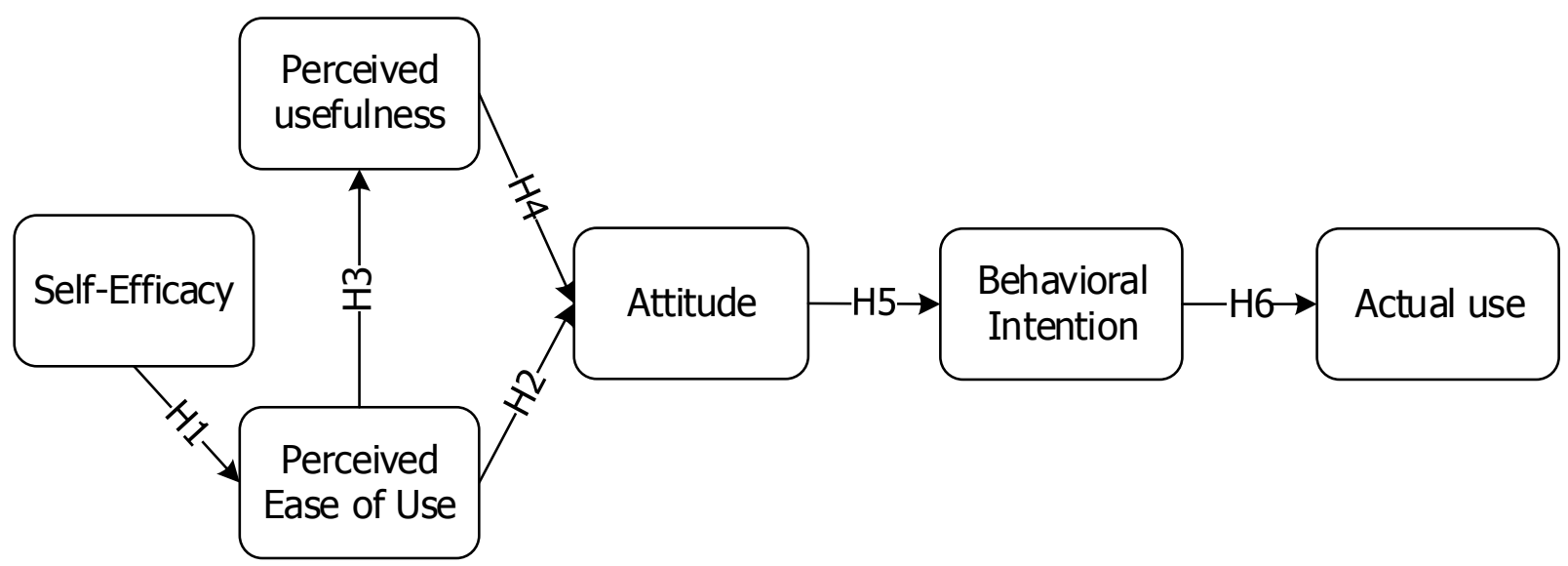

Figure 1. Research model

\section{Self-Efficacy}

Self-efficacy can be defined as a judgment of students' ability to use a system (Bandura, 1997). Students with a "high computer self-efficacy are more likely to choose and participate in computer-related activities, expect success in these activities, persist and employ effective coping behaviors when encountering difficulty, and exhibit higher levels of performance" than the students with a low computer self-efficacy (Compeau \& Higgins, 1995). Accordingly, students' competence and confidence in distance education tools and systems may play a significant role in the ease of use of these tools and systems. Therefore, self-efficacy would positively affect perceived ease of use of distance education tools and systems (H1).

\section{Perceived Ease of Use}

Perceived ease of use can be defined as the degree to which a student believes that using distance education tools and systems is free from effort (Davis, 1989). The complexity of distance education tools and systems depends on how easy it is to use these tools and systems such as screen capturing tools, authoring tools, LMSs, and virtual classroom systems. The easier it is to use these tools and systems, the more positive attitudes toward using these tools and systems (H2) and the easier and quicker perception of the advantages provided by them (H3).

\section{Perceived Usefulness}

Perceived usefulness can be defined as the degree to which an individual believes that using distance education tools and systems would enhance his or her success and performance (Davis, 1989). The main functionalities of distance education tools and systems enable users effectively develop interactive content and manage web-based courses. Therefore, perceived usefulness would positively affect students' attitudes toward using distance education tools and systems (H4).

\section{Attitudes, Behavioral Intentions, and Actual Use}

Attitudes toward using a new system is defined as a student's overall affective reaction to use the system (Davis, 1989). However, intention to use can be defined as the degree of an individual's belief that he or she will use distance education tools and systems (Venkatesh, Morris, Davis, \& Davis, 2003). Ajzen's Theory of Planned Behavior (TPB) (Ajzen, 1991) implies that the more favorable the students' attitudes toward distance education tools and systems, the greater will be their intention to use these tools and systems. Therefore, it is hypothesized that attitudes toward distance education tools and systems would positively affect behavioral intentions (H5), which would have a significant positive effect on actual use (H6). 


\section{METHOD}

\section{Research Design}

To make the study ecologically valid, the study was conducted in students' classrooms during their regularly scheduled Distance Education classes. At the start of the study, the students were given $\mathbf{3 0}$ minutes to complete a paper based pretest (conceptual knowledge measure). The students received instructions from the researcher about distance education theory for seven weeks (four hours per week). Then they received instructions from the researcher about tools and systems used in distance education for another seven weeks. At the end of the intervention, the students were given $\mathbf{3 0}$ minutes to individually complete the posttest, which was identical to the pretest. Finally, an online survey was administered to the students using an Internet based surveying system.

\section{Sample}

The target population of this research is undergraduate students majoring in Computer Education and Instructional Technology in Turkey. From this population, a total of 124 students who were selected using convenience sampling willingly participated in the study. The participants' ages ranged from 18 to 29 years (mean $=20.98, S D=1.63$ ). In terms of college status, majority of the participant (\%97.6) were juniors. Meanwhile, $72(\% 58)$ of the participants were women. The participants had little knowledge about distance education tools and systems prior to participating. This limited prior knowledge was verified through the analysis of the students' pretest scores.

\section{Instrument}

The conceptual knowledge measure used for the pretest and posttest consisted of ten multiple choice questions regarding distance education tools and systems, including screen capturing tools (Captivate and Camtasia), authoring tools (i-Spring and Articulate), LMSs (Moodle, Edmodo, Canvas, ALMS, and Docebo), and virtual classroom systems (Adobe Connect, Perculus, and Big Blue Button).

A scale developed Davis (1989) was used to measure perceived ease of use and perceived usefulness. In addition, items measuring attitude and behavioral intention were adapted from the TPB (Ajzen, 1991). The items measuring self-efficacy were adapted from the relevant literature (Compeau \& Higgins, 1995). Thus, the instrument has a total of 23 items, including 4 items for self-efficacy, 5 items for perceived usefulness, 3 items for perceived ease of use, 4 items for attitude, 3 items for behavioral intention, and 4 items for actual use. Participants were asked to indicate their level of agreement using a five-point Likert scale ranging from "strongly disagree" to "strongly agree."

\section{RESULTS}

\section{Pretest-posttest Results}

A paired-samples t-test using SPSS version 22.0 (SPSS, Chicago, IL, USA) was conducted to compare students' learning before and after the intervention. The mean posttest score $(M=8.2, S D=1.3)$ was higher than the mean pretest $\mathrm{score}(M=1.6, \mathrm{SD}=1.8)$, and the difference was statistically significant $(t=-21.64, p<.001)$. This implies that students had significant learning by participating in the instruction.

\section{Instrument Validity and Reliability}

Prior to conducting the main analyses, the data set was checked for the adequacy of factor analysis through with Kaiser-Meyer-Olkin (KMO) measure of sampling adequacy and Bartlett's test of sphericity (Bartlett, 1951; Kaiser, 1970). Table 1 shows the suitability of the data set for factor analysis. In addition to KMO, the results of Bartlett's test of sphericity verified the sampling adequacy of the data set for factorability. 
Table 1. The suitability of the data for factor analysis

\begin{tabular}{llll}
\hline & KMO & Chi-Square & Sig. \\
\hline Self-efficacy & .81 & 273.79 & .001 \\
Perceived usefulness & .89 & 672.62 & .001 \\
Perceived ease of use & .73 & 202.15 & .001 \\
Attitude & .81 & 401.03 & .001 \\
Behavioral Intention & .76 & 393.93 & .001 \\
Actual Use & .83 & 314.00 & .001 \\
\hline
\end{tabular}

Exploratory factor analysis (EFA) was employed using principal components extraction to assess the construct validity of the scales. The Bartlett's test of sphericity demonstrated the measures for the constructs are interdependent and the KMO measure of sampling adequacy is well above the minimally accepted level of .50 (Leech, Barrett, \& Morgan, 2005). The percentage of total variance explained ranged from 71.86 to 91.35 , which are higher than the acceptable value of .40 for measures with one factor (Scherer, Wiebe, Luther, \& Adams, 1988). Furthermore, each measurement item has a factor loading above .81 and a communality value above .66; both are higher than the acceptable value of .40 (Field, 2005). The corrected item-total correlation coefficients ranged from .47 to .89, suggesting moderate to high homogeneity of the items.

Average variance extracted (AVE) values equal or exceed .50 (Hair, Anderson, Tatham, \& Black, 2006), indicating the convergent validity for the constructs of the measurement model is adequate. Finally, reliability analysis indicated the instrument has a strong internal consistency in that Cronbach's alpha values ranged from .88 to .95, suggesting good to very good internal consistency (Creswell, 2005). The results of principal component analysis (factor loadings, total variance explained, and communality values), internal consistency reliability measures (corrected item-total correlations and Cronbach's a values) and convergent validity measures (composite reliability (CR) and AVE values) were shown in Table 2.

Table 2. Reliability and validity evidence

\begin{tabular}{|c|c|c|c|c|c|c|c|c|}
\hline \multirow[t]{2}{*}{ Construct } & \multirow[t]{2}{*}{ Item } & \multicolumn{5}{|c|}{ Internal reliability } & \multicolumn{2}{|c|}{$\begin{array}{c}\text { Convergent } \\
\text { validity }\end{array}$} \\
\hline & & $\begin{array}{l}\text { Cronbach's } \\
\text { alpha }\end{array}$ & $\begin{array}{l}\text { Item-total } \\
\text { correlation }\end{array}$ & $\begin{array}{l}\text { Factor } \\
\text { loading }\end{array}$ & $\begin{array}{c}\text { Comm } \\
\text { unality }\end{array}$ & $\begin{array}{c}\text { Total } \\
\text { variance } \\
\text { explained }\end{array}$ & CR & AVE \\
\hline Self-efficacy & $\begin{array}{l}\text { Se1 } \\
\text { Se2 } \\
\text { Se3 } \\
\text { Se4 }\end{array}$ & .88 & $\begin{array}{l}.78 \\
.81 \\
.73 \\
.68 \\
\end{array}$ & $\begin{array}{l}.88 \\
.90 \\
.85 \\
.81 \\
\end{array}$ & $\begin{array}{l}.78 \\
.81 \\
.72 \\
.66 \\
\end{array}$ & 74.18 & .79 & .50 \\
\hline $\begin{array}{l}\text { Perceived } \\
\text { ease of use }\end{array}$ & $\begin{array}{l}\text { PEU1 } \\
\text { PEU2 } \\
\text { PEU3 } \\
\end{array}$ & .88 & $\begin{array}{l}.81 \\
.77 \\
.74 \\
\end{array}$ & $\begin{array}{l}.92 \\
.90 \\
.88 \\
\end{array}$ & $\begin{array}{l}.85 \\
.81 \\
.77 \\
\end{array}$ & 81.05 & .77 & .50 \\
\hline $\begin{array}{l}\text { Perceived } \\
\text { usefulness }\end{array}$ & $\begin{array}{l}\text { PU1 } \\
\text { PU2 } \\
\text { PU3 } \\
\text { PU4 } \\
\text { PU5 }\end{array}$ & .95 & $\begin{array}{l}.93 \\
.91 \\
.86 \\
.82 \\
.80 \\
\end{array}$ & $\begin{array}{l}.96 \\
.95 \\
.92 \\
.89 \\
.87\end{array}$ & $\begin{array}{l}.91 \\
.90 \\
.84 \\
.78 \\
.75 \\
\end{array}$ & 83.65 & .76 & .51 \\
\hline Attitude & $\begin{array}{l}\text { AT1 } \\
\text { AT2 } \\
\text { AT3 } \\
\text { AT4 }\end{array}$ & .93 & $\begin{array}{l}.80 \\
.86 \\
.83 \\
.84 \\
\end{array}$ & $\begin{array}{l}.89 \\
.92 \\
.91 \\
.91 \\
\end{array}$ & $\begin{array}{l}.79 \\
.85 \\
.82 \\
.83 \\
\end{array}$ & 82.27 & .89 & .63 \\
\hline $\begin{array}{l}\text { Behavioral } \\
\text { Intention }\end{array}$ & $\begin{array}{l}\text { BI1 } \\
\text { BI2 } \\
\text { BI3 }\end{array}$ & .95 & $\begin{array}{l}.86 \\
.92 \\
.92 \\
\end{array}$ & $\begin{array}{l}.94 \\
.97 \\
.96\end{array}$ & $\begin{array}{l}.88 \\
.94 \\
.93\end{array}$ & 91.35 & .92 & .74 \\
\hline Actual use & $\begin{array}{l}\text { AU1 } \\
\text { AU2 } \\
\text { AU3 } \\
\text { AU4 }\end{array}$ & .90 & $\begin{array}{l}.79 \\
.80 \\
.80 \\
.76\end{array}$ & $\begin{array}{l}.89 \\
.89 \\
.89 \\
.87\end{array}$ & $\begin{array}{l}.78 \\
.80 \\
.79 \\
.75\end{array}$ & 71.86 & .87 & .62 \\
\hline
\end{tabular}




\section{Common Method Bias}

Harman's one-factor test was used to assess common method bias (Podsakoff, MacKenzie, Lee, \& Podsakoff, 2003). All the dependent and independent variables were subjected to an EFA using unrotated principal components factor analysis, principal component analysis with varimax rotation, and principal axis analysis with varimax rotation. The results suggested the presence of six factors with eigenvalues higher than one. The six factors together accounted for $\mathbf{7 6 . 4 3 \%}$ of the total variance, while the first factor explained $\mathbf{2 8 . 8 1 \%}$ of the total variance. Further, confirmatory factor analysis (CFA) showed that the one-factor model did not fit the data $[\times 2 / \mathrm{df}=3.94$, GFI $=.60$, AGFI $=.51$, NFI $=.74$, NNFI= $.77, \mathrm{IFI}=.79, \mathrm{SRMR}=.50, \mathrm{RMR}=.36, \mathrm{CFI}=.79, \mathrm{RMSEA}=.155]$. These results suggested that common method bias is not of a concern in the data set.

\section{The Structural Model}

Structural equation modeling (SEM) was conducted via maximum likelihood using SPSS AMOS (version 22.0) to test the research model. SEM is one of the most effective and reliable multivariate analysis methods for examining the factor structure of the measures and testing the hypothesized relationships among observed and latent variables (Byrne, 2010). The model produced good fit indices as shown in Table 3 . The value of Chi-square/df is 1.11; according to Kline (2005); a ratio of less than three is acceptable, whereas a ratio of less than two is good. The results of the CFA demonstrated all scales used in this study form adequate measurement models, and therefore, provide evidences for the construct validity of the measures.

Table 3. Model fit indices

\begin{tabular}{lll}
\hline & Model & Acceptable Fit Values \\
\hline X2 & $\mathbf{1 0 7 . 7 3 4}$ & \\
p value & .214 & $.05 \leq \mathrm{p} \leq 1.00$ (Hoyle, 1995) \\
X2/df & 1.11 & $<3$ (Kline, 2005) \\
GFI & .91 & $\geq .90$ (Hair et al., 2006) \\
AGFI & .87 & $\geq .80$ (Marsh, Balla, \& McDonald, 1988) \\
SRMR & .033 & $\leq .10$ (Kline, 2005) \\
RMR & .024 & $<.05$ (McDonald \& Moon-Ho, 2002) \\
RMSEA & .030 & $<.08$ (Hair et al., 2006) \\
NFI & .95 & $\geq .90$ (Hair et al., 2006) \\
NNFI & .99 & $\geq .90$ (Bentler \& Bonett, 1980) \\
CFI & .99 & $\geq .90$ (Bentler, 1990) \\
IFI & .99 & $\geq .90$ (Bollen, 1989) \\
PNFI & .77 & \\
\hline
\end{tabular}

\section{Hypothesis Testing}

Hypothesized relationships were tested through a structural model which was developed based on the TAM. The results indicated all proposed path coefficients among the observed and latent variables are significant $(p<.001)$. Figure 2 shows the results of the SEM analysis, including the path coefficients with significance levels along with R-squared values and respected error terms. The paths specified in the model account for $97 \%$ of the variance in actual use. 


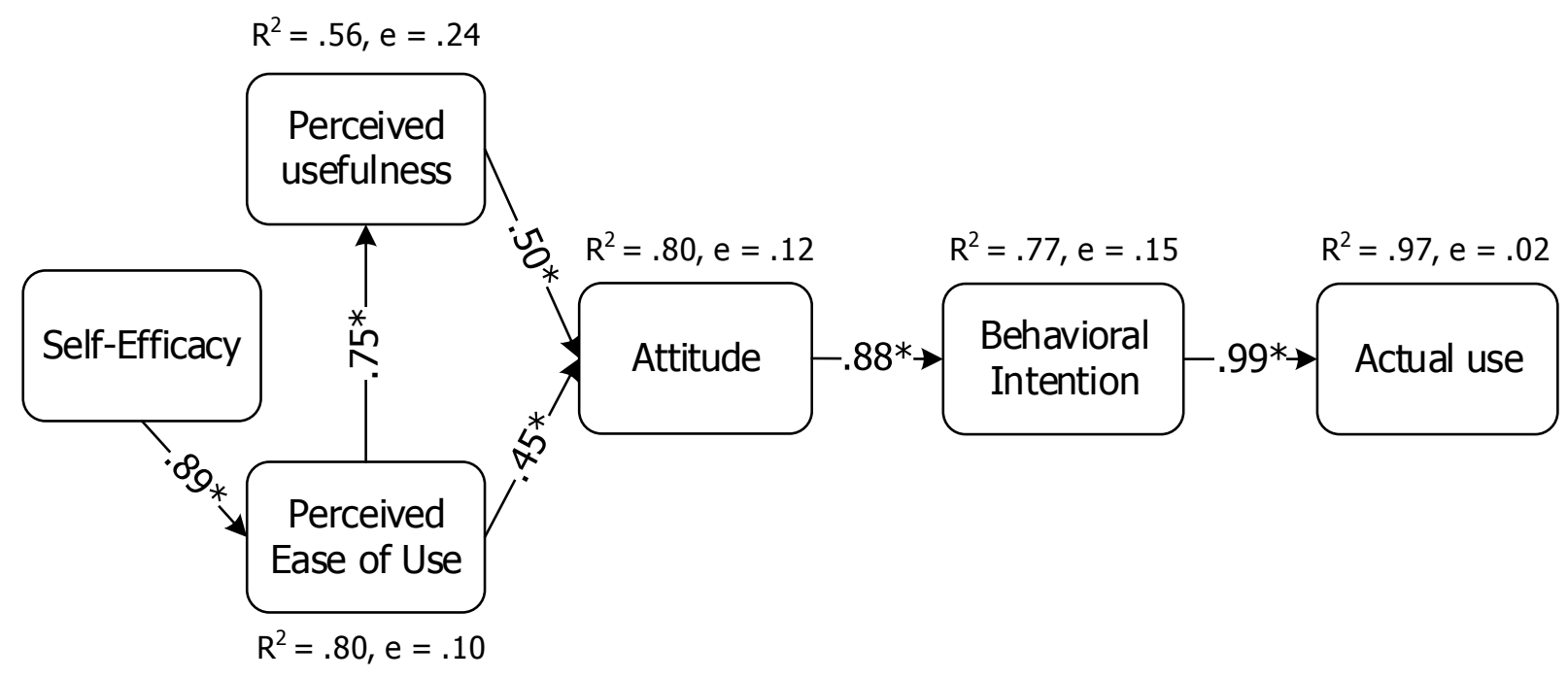

Chi-Square $=107.734, \mathrm{df}=97, \mathrm{Chi}-$ Square $/ \mathrm{df}=1.11, P$-value $=.21, \mathrm{GFI}=.91, \mathrm{RMSEA}=.030, * p<.001$.

Figure 2. Causal model of the students' use of distance education tools and systems

A summary of the hypothesis testing results is given below:

H1. Self-efficacy would positively affect perceived ease of use $(\beta=.89 ; t=8.99$; $p<.001)$.

H2. Perceived ease of use would positively affect students' attitudes toward using distance education tools and systems $(\beta=.45 ; t=5.09 ; p<.001)$.

H3. Perceived ease of use would positively affect perceived usefulness $(\beta=.75$; $t=9.29 ; p<.001)$.

H4. Perceived usefulness would positively affect students' attitudes toward using distance education tools and systems $(\beta=.50 ; t=5.93 ; p<.001)$.

H5. Attitudes would positively affect students' intentions to use distance education tools and systems $(\beta=.88 ; t=11.36 ; p<.001)$.

H6. Behavioral intentions would positively affect actual use $(\beta=.99 ; t=14.67$; $p<.001)$.

\section{DISCUSSION AND CONCLUSION}

This study proposed a research model based on the TAM to investigate key factors affecting attitudes and behavioral intentions toward using distance education tools and systems. The proposed model suggested that perceptions of perceived ease of use is anchored to selfefficacy. Additionally, consistent with the TAM, it suggested both perceived usefulness and perceived ease of use are significant in explaining the attitudes toward using distance education tools and systems.

The CFA results showed that the proposed model indicates a reasonable fit to the data with the following fit indices; $[X 2 / D F=1.11, \mathrm{GFI}=.91, \mathrm{AGFI}=.87, \mathrm{NNFI}=.99, \mathrm{NFI}=.95, \mathrm{CFI}=$ $.99, \mathrm{IFI}=.99$, and RMSEA $=.030]$. The research model, which explains $97 \%$ of the variance in actual use, has a strong predictive power. The high proportion of the variance explained suggested that the model includes a significant portion of factors that might affect actual use.

Consistent with the hypotheses, the results showed that self-efficacy is directly related with perceived ease of use and indirectly related with attitudes and behavioral intentions. 
The results also showed the usefulness and ease of use perceptions have significant effects on the attitudes. However, the perceived usefulness to have a greater correlation with system use than those of perceived ease of use. Moreover, the attitudes have a significant and positive effect on behavioral intentions, which have a significant and positive effect on actual use.

The fact that perceived usefulness has a significant effect on attitudes suggests the participants believe that distance education tools and systems would be a useful to do their work. Furthermore, they think that using these tools and systems would increase their productivity, enhance their effectiveness, improve their performance, and ease their job. The results also indicated that perceived ease of use has a significant effect on the attitudes. This suggests that the participants find it easy to become skillful at using distance education tools and systems and they believe that their interaction with these tools and systems would be clear and understandable.

The present study has important research implications. First, the results indicated the research model explains the variance of the dependent variable better than the TAM, which does not explicitly include any individual characteristics. However, self-efficacy in the proposed model may capture unique variance in attitudes and intentions. Second, the traditional TAM constructs provide very general information on students' opinions about distance education tools and systems. Whereas, the research model delivers more specific information by including the self-efficacy. Therefore, the proposed model is more likely to capture situation-specific factors.

The findings have several practical implications for instructional designers, instructors, and policy makers. First, the tools and systems investigated in this study provide great platforms for managing online learning environment where instructors can enrich teaching materials, and support new pedagogies that focus on interactive tools for inquiry based pedagogies and collaborative workspaces. This implies that not only instructional designers but also instructors need to be equipped with the acquired literacy and skills regarding these tools and systems. Finally, it is important to note that policy makers should develop new pedagogies and update the related curriculum that support these new skills. Otherwise, integrating these emerging tools and systems to traditional teaching practices may hinder the design of effective online learning environments as they require intensive teacher-student interactions.

The present study investigated factors affecting use of tools and systems used in distance education focusing only on the self-efficacy. Future research should therefore focus on the impact of other individual characteristics such as self-regulation and autonomy on users' attitudes toward adoption of distance education systems. Finally, it may be useful to employ a mixed method approach that incorporates both qualitative and quantitative methods for a deeper investigation of the key factors affecting use of such systems.

\section{BIODATA and CONTACT ADDRESSES of AUTHOR}

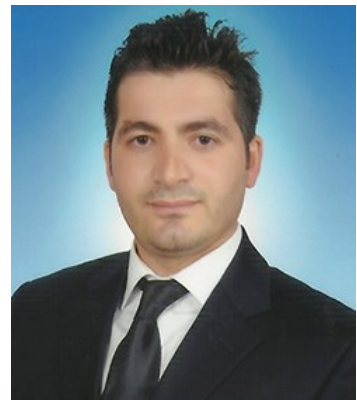

Ibrahim ARPACI is Assist. Professor and Chair of the Department of Computer Education and Instructional Technology and Director of Distance Education Application and Research Center at Gaziosmanpasa University. He was a visiting scholar at Ryerson University, Ted Rogers School of Information Technology Management, Toronto, ON, Canada (2012-2013). He holds a BSc in Computer Education and Instructional Technology (2005) from Anadolu University, an MSc in Information Systems (2009) and a PhD in Information Systems (2013) both from Middle East Technical University. His research interests are in educational technology, behavior and learning, and distance education. 
Assist. Prof. Dr. Ibrahim ARPACI

Department of Computer Education and Instructional Technology,

Faculty of Education, Gaziosmanpasa University, 60250, Tokat, TURKEY

Phone: +903562521616 ,

E-mail: ibrahim.arpaci@gop.edu.tr

\section{REFERENCES}

Ajzen, I. (1991). The theory of planned behavior. Organizational Behavior and Human Decision Processes, 50(2), 179-211.

Bandura, A. (1977). Self-efficacy: Toward a unifying theory of behavioral change. Psychological Review, 84, 191-215. doi:10.1037/0033-295x.84.2.191

Bandura, A. (1997). Self-efficacy: The exercise of control. New York, NY: Worth.

Bartlett, M. S. (1951). The effect of standardization on a X2 approximation in factor analysis. Biometrika, 38(3/4), 337-344.

Bentler, P. M. (1990). Comparative fit indexes in structural models. Psychological Bulletin, 107, 238-246.

Bentler, P. M., \& Bonett, D. G. (1980). Significance tests and goodness-of-fit in the analysis of covariance structures. Psychological Bulletin, 88, 588-606.

Berge, Z. (1999). Interaction in post-secondary Web-based learning. Educational Technology, 39(1), 5-11.

Bollen, K. A. (1989). Structural equations with latent variables. New York: Wiley.

Byrne, B. M. (2010). Structural equation modeling with Amos: Basic concepts, applications, and programming (2nd ed.). New York, NY: Taylor and Francis Group.

Cho, M. H., \& Shen, D. (2013). Self-regulation in online learning. Distance education, 34(3), 290-301.

Compeau, D. R., \& Higgins, C. A. (1995). Computer self-efficacy: Development of a measure and initial test. MIS Quarterly, 19(2), 189-211.

Creswell, J. W. (2005). Educational research: Planning conducting and evaluating quantitative and qualitative approaches to research (2nd Ed.). Upper Saddle River, NJ: Merrill/Pearson Education.

Davis, F. D. (1989). Perceived usefulness, perceived ease of use, and user acceptance of information technology. MIS Quarterly, 13(3), 319-340.

Dunn, K. E., Rakes, G. C., \& Rakes, T. A. (2014). Influence of academic self-regulation, critical thinking, and age on online graduate students' academic help-seeking. Distance Education, 35(1), 75-89.

Field, A. (2005). Discovering statistics using SPSS. Thousand Oaks, CA: SAGE.

Flottemesch, K. (2000). Building effective interaction in distance education: A review of the literature. Educational Technology, 40(3), 46-51.

Hair, J. F., Tatham, R. L., Anderson, R. E., \& Black, C. W. (2006). Multivariate data analysis. Upper Saddle River, NJ: Pearson Prentice Hall. 
Hoyle, R. H. (1995). The structural equation modeling approach: Basic concepts and fundamental issues. In R. H. Hoyle (eds.), Structural equation modeling: Concepts, issues, and applications, (pp. 1-15). Thousand Oaks, CA: Sage Publications.

Kaiser, H. F. (1970). A second generation little jiffy. Psychometrika, 35(4), 401-415.

Kline, R. B. (2005). Principles and practice of structural equation modeling. New York: The Guilford Press.

Kozar, O., Lum, J. F., \& Benson, P. (2015). Self-efficacy and vicarious learning in doctoral studies at a distance. Distance Education, 36(3), 448-454.

Lee, C. Y. (2015). Changes in self-efficacy and task value in online learning. Distance Education, 36(1), 59-79.

Leech, N. L., Barrett, K. C., \& Morgan, G. A. (2005). SPSS for intermediate statistics: Use and interpretation (2nd Ed.). Hillsdale, NJ: Lawrence Erlbaum.

Marsh, H. W., Balla, J. R., \& McDonald, R. P. (1988). Goodness-of-fit indexes in confirmatory factor analysis: The effect of sample size. Psychological Bulletin, 103(3), 391-410.

McDonald, R. P., \& Moon-Ho, R. H. (2002). Principles and practice in reporting structural equation analysis. Psychological Methods, $7(1), 64-82$.

Moore, M., \& Kearsley, G. (1996). Distance education: A systems view. Belmont, CA: Wadsworth.

Podsakoff, P. M., MacKenzie, S. B., Lee, J. Y., \& Podsakoff, N. P. (2003). Common method biases in behavioral research: A critical review of the literature and recommended remedies. Journal of Applied Psychology, 88(5), 879-903.

Ritzhaupt, A. D., \& Kumar, S. (2015). Knowledge and Skills Needed by Instructional Designers in Higher Education. Performance Improvement Quarterly, 28(3), 51-69.

Saba, F. (1999). Architecture of dynamic distance instructional and learning systems. Distance Education Report, 3(8), 1-5.

Scherer, R. F., Wiebe, F. A., Luther, D. C., \& Adams, J. S. (1988). Dimensionality of coping: Factor stability using the ways of coping questionnaire. Psychological Reports, 62, 763-770.

Schlosser, L. A., \& Simonson, M. R. (2009). Distance education; definitions and glossary of terms. Bloomington, IN: IAP.

Venkatesh, V., Morris, M. G., Davis, G B., \& Davis, F. D. (2003). User acceptance of information technology: Toward a unified view. MIS Quarterly, 2J(3), 425-478.

Wang, C. H., Shannon, D. M., \& Ross, M. E. (2013). Students' characteristics, self-regulated learning, technology self-efficacy, and course outcomes in online learning. Distance Education, 34(3), 302-323.

Zimmerman, B. J. (2000). Self-efficacy: An essential motive to learn. Contemporary Educational Psychology, 25, 82-91. doi:10.1006/ceps.1999.1016. 